\title{
BMJ open Identifying future 'unexpected' survivors: a retrospective cohort study of fatal injury patterns in victims of improvised explosive devices
}

\author{
James A G Singleton, ${ }^{1,4}$ lain E Gibb, ${ }^{2}$ Nicholas C A Hunt, ${ }^{3}$ Anthony M J Bull, ${ }^{1}$ \\ Jonathan C Clasper ${ }^{1,4}$
}

To cite: Singleton JAG, Gibb IE, Hunt NCA, et al. Identifying future 'unexpected' survivors: a retrospective cohort study of fatal injury patterns in victims of improvised explosive devices. BMJ Open 2013;3: e003130. doi:10.1136/ bmjopen-2013-003130

- Prepublication history for this paper is available online To view these files please visit the journal online (http://dx.doi.org/10.1136/ bmjopen-2013-003130)

Received 26 April 2013 Revised 21 June 2013 Accepted 24 June 2013

For numbered affiliations see end of article.

Correspondence to Dr James Singleton; j.singleton11@ic.ac.uk

\section{ABSTRACT}

Objectives: To identify potentially fatal injury patterns in explosive blast fatalities in order to focus research and mitigation strategies, to further improve survival rates from blast trauma.

Design: Retrospective cohort study.

Participants: UK military personnel killed by improvised explosive device (IED) blasts in Afghanistan, November 2007-August 2010.

Setting: UK military deployment, through NATO, in support of the International Security Assistance Force (ISAF) mission in Afghanistan.

Data sources: UK military postmortem CT records, UK Joint Theatre Trauma Registry and associated incident data.

Main outcome measures: Potentially fatal injuries attributable to IEDs.

Results: We identified 121 cases, 42 mounted (in-vehicle) and 79 dismounted (on foot), at a point of wounding. There were 354 potentially fatal injuries in total. Leading causes of death were traumatic brain injury $(50 \%, 62 / 124$ fatal injuries), followed by intracavity haemorrhage $(20.2 \%$, $25 / 124$ ) in the mounted group, and extremity haemorrhage (42.6\%, 98/230 fatal injuries), junctional haemorrhage (22.2\%, 51/230 fatal injuries) and traumatic brain injury $(18.7 \%, 43 / 230$ fatal injuries) in the dismounted group. Conclusions: Head trauma severity in both mounted and dismounted IED fatalities indicated prevention and mitigation as the most effective strategies to decrease resultant mortality. Two-thirds of dismounted fatalities had haemorrhage implicated as a cause of death that may have been anatomically amenable to prehospital intervention. One-fifth of the mounted fatalities had haemorrhagic trauma which currently could only be addressed surgically. Maintaining the drive to improve all haemostatic techniques for blast casualties, from point of wounding to definitive surgical proximal vascular control, alongside the development and application of novel haemostatic interventions could yield a significant survival benefit. Prospective studies in this field are indicated.

\section{INTRODUCTION}

Currently, the improvised explosive device (IED) is the most prevalent cause of fatal battlefield injury. ${ }^{1}$ The US Department of

\section{ARTICLE SUMMARY}

Article focus

- We investigated the cause of death in modern battlefield fatalities following improvised explosive device (IED) blasts with cohorts of both dismounted (on foot) and mounted (in-vehicle) troops, in order to direct future research and treatment directions.

- We hypothesised that the patterns of cause of death could be identified that would inform mitigation and novel treatment development in both military and civilian domains.

\section{Key messages}

- We describe the potentially fatal injury profile due to IEDs for both dismounted and mounted casualties for the first time.

- For dismounted IED fatalities, extremity and junctional (groin/axilla/neck) haemorrhage are significant, potentially treatable, causes of death.

- In-vehicle IED casualties most frequently die of head injuries too severe to be treatable. Efforts to reduce the impact of such injuries should be made through mitigating/preventative strategies.

Strengths and limitations of this study

- This is the largest series of IED fatalities reported to date with comprehensive CT and autopsy records. Studies such as this are invariably retrospective due to the constraints of battlefield trauma research, but meaningful analysis can still be performed-indeed there is an imperative to analyse death data to minimise future potential loss of life.

Defense has defined IEDs as 'devices placed or fabricated in an improvised manner incorporating destructive, lethal, noxious, pyrotechnic or incendiary chemicals, designed to destroy, disfigure, distract or harass and often incorporating military stores'. ${ }^{2}$ IEDs have been shown to generate a different injury profile compared to conventional munitions, and blast injuries 
secondary to IEDs are also relatively less well characterised. ${ }^{3}$ It is important to note that IED strikes are not limited to Middle Eastern warzones. For 2012, excluding Iraq or Afghanistan, more than 500 IED strikes occurred per month worldwide (mean monthly rates in Afghanistan for 2011-2012 were over 1300). ${ }^{4}$ Victims may be in vehicles (mounted) or in the open (dismounted). Therefore, advances in both mitigating and treating the effects of IEDs could benefit not just military medicine and force protection but also civilian medical practice and counter-IED technologies.

Combat casualty care has undergone significant advances in recent years. Progress has been made in multiple areas, including improved personal protective equipment for troops, innovations in prehospital care, expedited casualty evacuation and new in-hospital damage control resuscitation protocols optimised for battlefield trauma cases. Consequently, coalition forces are currently achieving the highest recorded survival rates from battlefield injury-greater than $90 \%$ in Afghanistan compared to $85 \%$ in Vietnam and $80 \%$ in World War II. ${ }^{5}$ These modern survival rate statistics include cases with such severe injuries that until recently they would have been considered unexpected survivors. ${ }^{6}$ Sadly, certain injuries remain fatal. However, while some trauma may always be genuinely unsurvivable, other injuries, currently untreatable, may yet be amenable to intervention in the future. To identify these potential 'future unexpected survivors', an urgent requirement exists to analyse IED blast death data. Characterisation of resultant injury patterns can contribute to informing prevention, mitigation and clinical strategies and research activity. This can then bring about further improvements in blast casualty care, both military and civilian.

All UK military combat fatalities undergo formal autopsy by a forensic pathologist following repatriation to the UK. Furthermore, in November 2007, full body postmortem CT (PM-CT) imaging was adopted by the UK military. PM-CT scans are performed at the deployed field hospitals-previously in Iraq and currently in Afghanistan-as soon as feasible after death. Use of forensic CT imaging was first reported in 1977 as an adjunct to traditional physical postmortem examination, ${ }^{7}$ yet has risen to prominence as a frequently used forensic investigation in only the last $10-15$ years. ${ }^{8} 9$ Some have even suggested that cross-sectional imaging techniques-combined CT and MRI-have the potential to replace traditional autopsy. ${ }^{10}$ This remains a controversial subject and this study is neither advocating nor opposing this view. There can be little doubt, however, that PM-CT is of considerable value to forensic pathologists in circumstances involving trauma, especially skeletal injury and foreign material detection, ${ }^{11}{ }^{12}$ both of which are highly relevant in combat casualties. Therefore, with autopsy and PM-CT imaging, multimodal tools now exist with which to document and learn from fatal battlefield injury with access to high levels of anatomical detail never previously available.
We investigated the cause of death in modern battlefield fatalities following IED blasts with cohorts of both dismounted and mounted troops, in order to direct future research and treatment directions. We hypothesised that patterns of cause of death could be identified that would inform mitigation and novel treatment development in both military and civilian domains.

\section{METHODS}

Custodianship of the PM-CT images rests with Her Majesty's Coroners. Therefore, we obtained permission to access the PM-CT dataset prior to starting the study. Permission was also granted by Home Office accredited forensic pathologists to analyse relevant autopsy data and the study was approved by UK Joint Medical Command.

Inclusion criteria were any UK military IED deathboth died of wounds (DOW) (ie, died following arrival at a medical facility) and killed in action (KIA) (ie, certified dead prior to arrival at a medical facility) cases-with available PM-CT imaging and available UK Joint Theatre Trauma Registry (JTTR) data occurring within the study period. The UK JTTR is a prospectively collected trauma database of every UK military casualty admitted to a medical facility or killed on deployed operations, and includes details of any surgery prior to death. In the case of fatalities, a military research nurse attends the formal autopsy performed once the body has been repatriated to the UK. The pathologist's findings are coded using Abbreviated Injury Scale (AIS) 2005-Military ${ }^{13}$ and then entered into the JTTR. Retrospective analysis was undertaken of all UK military personnel killed by IED blasts with available PM-CT imaging and relevant incident data from November 2007-inception of PM-CT imaging-to August 2010 The UK JTTR was interrogated for injury data, relevant incident data and casualty location at point of wounding (in-vehicle/mounted or on foot/dismounted). Intervals between time of wounding, time of death and time of PM-CT scan were recorded. Further detail concerning vehicle type or injury specifics beyond that presented here could not be published due to over-riding security/vulnerability issues. All PM-CT scans were reported by a single military consultant (IG) the UK's most experienced radiologist in reporting postmortem blast trauma imaging.

A cause of death analysis was performed. An anatomical trauma severity classification system was required and the AIS 2005-Military Edition was appropriate. This system identifies nine body regions (head, face, neck, thorax, abdomen, spine, upper extremities, lower extremities and external) and uses an anatomic ordinal scale to score trauma severity, from one (minor injury) to six (maximum injury, currently unsurvivable). The Injury Severity Score (ISS) evolved from the AIS and comprises an ordinal score from 1 to 75 . The nine regions were grouped into six (head/neck, face, chest, abdomen (including pelvic contents), extremities 
(including pelvic girdle) and external). The score consists of the sum of the squares of the three highest scoring regions. If an injury to any region scores 6 , the ISS is automatically 75 . The literature suggests that the ISS under-represents multiple injuries from the same anatomical region and so the New Injury Severity Score (NISS) was introduced, ${ }^{14}$ in which the score is the sum of the squares of the three highest scoring injuries regardless of region. Modern battlefield blast fatalities have been shown to sustain injuries to multiple AIS regions. ${ }^{15}$ This contrasts with the previous data from World War II, and the Korean and Vietnam Wars, where the majority of combat fatalities were observed to have sustained only one life threatening 'hit'. ${ }^{16}$ It has been argued that it is not possible to accurately determine the relative lethality of multiple potentially fatal injuries ${ }^{17}$; in the context of battlefield trauma, injuries with an AIS $\geq 4$ have significant lethal potential. ${ }^{13}$ We took these factors into account in devising our cause of death analysis methodology. Thus, equal weighting was given to all three injuries contributing to NISS and we excluded any injuries with AIS $\leq 3$. This generated the overall totals of potentially fatal injuries by AIS region. NISS was more appropriate than ISS given the frequency of multiple injuries to a single region in blast trauma, and because NISS has been shown to be a better predictor of mortality than ISS. ${ }^{14}$

We then assessed the mechanism of death for every fatal injury (AIS $\geq 4$ ). We classified haemorrhagic injuries as extremity-amenable to tourniquet control; junctional-potentially amenable to compression; or intracavity-requiring surgical haemostasis. It was necessary to amalgamate anatomically separate groups into unifying mechanistic groups. This helped to clarify intragroup trends and facilitate intergroup comparison; we combined groin, neck and axillary haemorrhagic injuries to form an overall junctional haemorrhage group. Upper and lower limb haemorrhagic injuries constituted the extremity haemorrhage group. Intracranial, intrathoracic and intra-abdominal bleeds made up the intracavity haemorrhage group. Of note, only a single open head injury contributed to this group. Head and spinal neurological injuries, including contained intracranial bleeds, contributed to the CNS injury group.

We performed statistical analysis using SPSS V.20.0 (IBM, Armonk, New York, USA). For initial cohort comparison, we used the Mann-Whitney U (MWU) test to compare ages of the mounted (M) and dismounted (DM) groups-these variables were not normally distributed (testing for normality using the Shapiro-Wilk test generated a $\mathrm{p}$ value of 0.023 for the $\mathrm{M}$ group and 0.001 for the DM group). We also compared time intervals, number of AIS regions sustaining lethal injury and total number of AIS regions injured per casualty using a Mann-Whitney U test, as these data sets were also nonparametric with Shapiro-Wilk $p$ values $<0.05$. We used Fisher's exact test for intergroup comparison of specific causes of death and mechanism of death. A $p$ value $<0.05$ was considered significant.

\section{RESULTS}

\section{Study group composition}

A total of 212 PM-CT death investigations were performed during the study period. This translated to a study group of 121 of which $42 / 121$ were $M$ at the time of wounding and 79/121 were in a DM environment when wounded (figure 1).

\section{Initial cohort comparison}

We found no significant differences between ages of the mounted and dismounted cohorts. In total, 120 of 121 cases were men. The median interval from injury to scan for all 121 cases was $313 \mathrm{~min}$ (IQR 224-780), comprising median intervals of $81 \mathrm{~min}$ between injury and death, and 232 min from death to CT scan (further details in table 1). The age profiles, wounding-death-scan intervals, KIA:DOW ratio and number of AIS regions with lethal injuries did not differ significantly between groups (table 1). All 62\% (26/42) of M fatalities and 56\% (44/ 79) of DM fatalities had potentially fatal injuries to two or more anatomical regions ( $\geq 2$ AIS regions contributing to the NISS score).

\section{Severity and anatomical burden of injury}

M fatalities had significantly higher NISS ( $p=0.012$, MWU) values compared to dismounted fatalities indicating greater injury burden (figure 2).

$\mathrm{M}$ fatalities suffered injuries to significantly more AIS regions than dismounted fatalities with median values of 6 and 4 regions injured, respectively. $(\mathrm{p}<0.0001 \mathrm{MWU}$; figure 3).

\section{Cause and mechanism of death in blast fatalities}

Clear differences were also evident in the anatomical distribution of fatal injuries in $\mathrm{DM}$ and $\mathrm{M}$ groups as shown in table 2. Of note, $9 / 363$ injuries making up the NISS scores were less than 4 , and were excluded from further analysis, leaving 354 fatal injuries in total.

Mechanism of death from these injuries was calculated, as previously described. The resultant chart is shown in figure 4.

\section{DISCUSSION}

\section{Fatal injury distribution and effect of environment on} extent of injuries

$\mathrm{M}$ and DM blast casualties presented here demonstrate significantly different potentially fatal injury profiles with respect to incidence of head, lower extremity and thoracic injuries $(\mathrm{p}<0.0001)$. Resultant mechanism of death also varied according to the location at the point of wounding. For mounted IED fatalities, CNS trauma (most commonly severe traumatic brain injury (TBI) rather than spinal cord trauma) was the leading mechanism of death, followed by intracavity haemorrhage. In 
Figure 1 Study group composition.

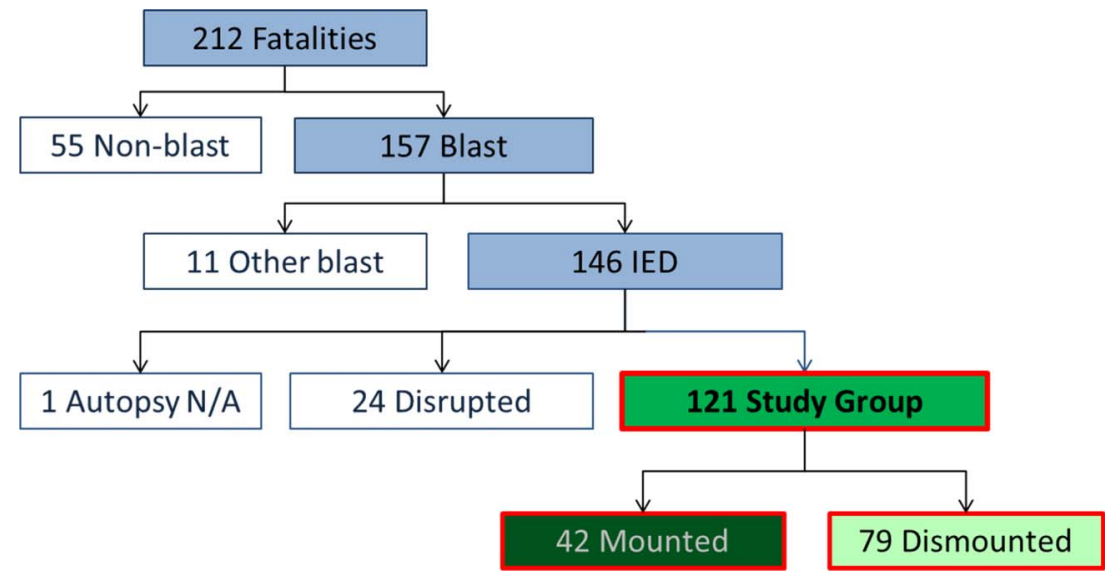

DM IED fatalities haemorrhage predominated, most commonly from extremity bleeding, followed by junctional blood loss.

This study also demonstrates that blast fatalities in vehicles are both more severely and more widely injured than dismounted blast fatalities. One might expect the vehicle to mitigate both the occupant's surface area affected by injurious components of the blast and the severity of injury sustained, but these hypotheses are not supported by our data. Clearly, type and size of IED will have a bearing on injury severity and distribution. ${ }^{3}{ }^{15}$ However, the sensitive nature of such munition data is self-evident and so any future work utilising such incident data would have to satisfy the understandable security issues.

\section{Strengths and weaknesses}

This is the largest series of IED fatalities reported to date with comprehensive CT and autopsy records. Studies such as these are invariably retrospective due to the constraints of battlefield trauma research, but meaningful analysis can still be performed-indeed, there is an imperative to analyse death data to minimise future potential loss of life.

This study was based on injury data from the UK JTTR rather than solely PM-CT findings. All injuries noted at autopsy are stored in the UK JTTR. Furthermore, PM-CT results were available to the investigating pathologist; therefore, the autopsy report can be considered a synergistic product of the radiological and physical investigations. Standard (ie, non-contrast) PM-CT has inherent limitations-essentially decreased sensitivity for vascular and hollow visceral injuries compared to formal autopsy. ${ }^{18}$ PM-CT angiography can redress this, but is an evolving science and is both time intensive and labour intensive compared to a standard CT scan, requiring invasive access to the femoral vessels, non-standard contrast media and a heart-lung bypass machine to temporarily restore circulation. ${ }^{19}$ This would not be appropriate considering the clinical work load at the military hospital at Camp Bastion, Afghanistan, where the PM-CTs are performed.

A potential weakness of PM-CT for trauma fatalities is the loss of diagnostic sensitivity secondary to artefact either from resuscitation and/or decomposition. However, autopsy was performed with the knowledge of any resuscitative procedures performed. Also, the median intervals between time of wounding and time of death were less than 90 min and those between the time of death and the time of scan were less than $4 \mathrm{~h}$ (and in cases with any significant delay to scan, the deceased were transferred to refrigerated mortuary conditions).

Table 1 Cohort comparison: mounted versus dismounted

\begin{tabular}{|c|c|c|c|c|c|}
\hline Group variable & & $\begin{array}{l}\text { Mounted } \\
(n=42)\end{array}$ & $\begin{array}{l}\text { Dismounted } \\
(n=79)\end{array}$ & $\begin{array}{l}\text { Overall } \\
(n=121)\end{array}$ & $\begin{array}{l}\text { M vs DM, } p \\
\text { value }\end{array}$ \\
\hline Age in years & & $25.5(22-30)^{\star}$ & $25.0(21-29)^{\star}$ & $25(21-29)^{\star}$ & 0.345 \\
\hline ToW-ToD in mins & & $78(36-113)^{\star}$ & $85(58-196)^{\star}$ & $81(50-145)^{*}$ & 0.110 \\
\hline ToD-ToS in mins & & $246(160-714)^{\star}$ & $216(89-900)^{*}$ & $232(105-712)^{*}$ & 0.234 \\
\hline KIA (\%) & & $38(90)$ & $70(89)$ & 108 & 1.000 \\
\hline DOW (\%) & & $4(10)$ & $9(11)$ & 13 & 1.000 \\
\hline Number of AIS regions with fatal injuries & 1 & $16(38)$ & $35(44)$ & 51 & 0.492 \\
\hline \multirow{2}{*}{ (\%) } & 2 & $22(52)$ & $38(48)$ & 60 & \\
\hline & $\geq 3$ & $4(10)$ & $6(8)$ & 10 & \\
\hline
\end{tabular}




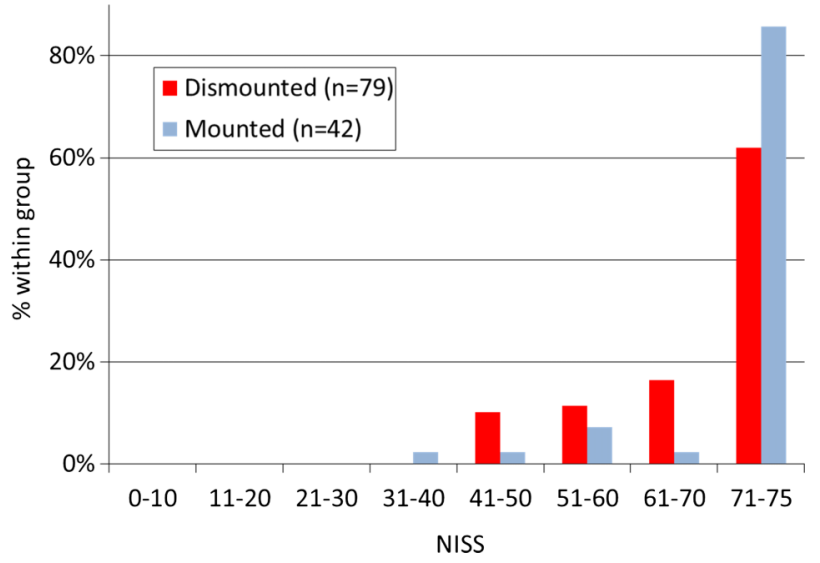

Figure 2 New Injury Severity Score (NISS) scores for mounted and dismounted fatalities.

Therefore, neither prior interventions nor decomposition artefact would have been likely to cause diagnostic issues in this study.

\section{Comparisons with other studies}

Such a comparison, as performed in our study, has not been presented previously for modern combat blast fatalities. To date, cause of death analyses for $\mathrm{M}$ and/or DM blast fatalities have tended to be reported with $\mathrm{M}$ fatalities as a separate group, ${ }^{15}$ as an amalgamated group, ${ }^{17}$ or amalgamated and in conjunction with other injury mechanisms such as gunshot wounds (GSWs), aircraft crashes and motor vehicle collisions (MVCs). ${ }^{20}$

Nelson $e t a l^{21}$ reported a case series of 18 US military IED casualties injured in Iraq in 2004, of whom 9 died. Injuries were described in individual narratives, and were recorded clinically. No post mortem examination/ imaging was reported. Of note, one of the three $\mathrm{M}$ fatalities and four of the six DM fatalities sustained severe head injuries. Our series also contained multiple cases
Table 2 Fatal injury rates by AIS region: mounted (M) versus dismounted (DM)

\begin{tabular}{|c|c|c|c|}
\hline \multirow[b]{2}{*}{ AIS region } & \multicolumn{2}{|c|}{$\begin{array}{l}\text { Percentage of fatal } \\
\text { injuries within group }\end{array}$} & \multirow{2}{*}{$\begin{array}{l}\text { M vs DM } \\
\text { CoD rates, } \\
p \text { value } \\
\text { (fishers) }\end{array}$} \\
\hline & $\begin{array}{l}M \\
(n=124)\end{array}$ & $\begin{array}{l}\text { DM } \\
(n=230)\end{array}$ & \\
\hline Head & $53 \%(66)$ & $19 \%(43)$ & $<0.0001$ \\
\hline Thorax & $23 \%(29)$ & $8 \%(18)$ & $<0.0001$ \\
\hline Lower extremity & $7 \%(9)$ & $48 \%(111)$ & $<0.0001$ \\
\hline Abdomen & $8 \%(10)$ & $13 \%(31)$ & 0.1636 \\
\hline Neck & $2 \%(2)$ & $3 \%(8)$ & 0.5039 \\
\hline Spine & $4 \%(5)$ & $3 \%(7)$ & 0.7594 \\
\hline Other trauma & $2 \%(2)$ & $1 \%(3)$ & 1.0000 \\
\hline Upper extremity & $1 \%(1)$ & $3 \%(7)$ & 0.2695 \\
\hline Face & $0 \%(0)$ & $1 \%(2)$ & 0.5435 \\
\hline
\end{tabular}

of fatal head trauma, indicating this to be a consistent injury pattern among IED fatalities.

Farkash $e t a l^{8}$ reported a case series of 22 Israeli Defence Force combat fatalities undergoing PM-CT from September 1997 to December 1998 following explosive trauma. Formal autopsy is frequently opposed in Israel on religious grounds and only four cases underwent physical autopsy. Furthermore, extremities were not CT scanned in the Israeli group (head, neck, chest, abdomen and pelvis only) and no summary injury severity data were presented. PM-CT demonstrated injuries to the head/neck in $86 \%(19)$, face $50 \%$ (11), chest $77 \%$ (17), abdomen $32 \%$ (7) and extremities $36 \%$ (8). Without injury severity data, little can be derived from further comparison, but this study clearly shows the utility of PM-CT in a military population.

In 2011, Eastridge et $a l^{22}$ published their findings on the cause of death in 558 died of wounds (DOW) the US combat fatalities from Iraq and Afghanistan from October 2001 until June 2009, thus including both
Figure 3 Abbreviated Injury Scale regions injured per death, mounted versus dismounted.

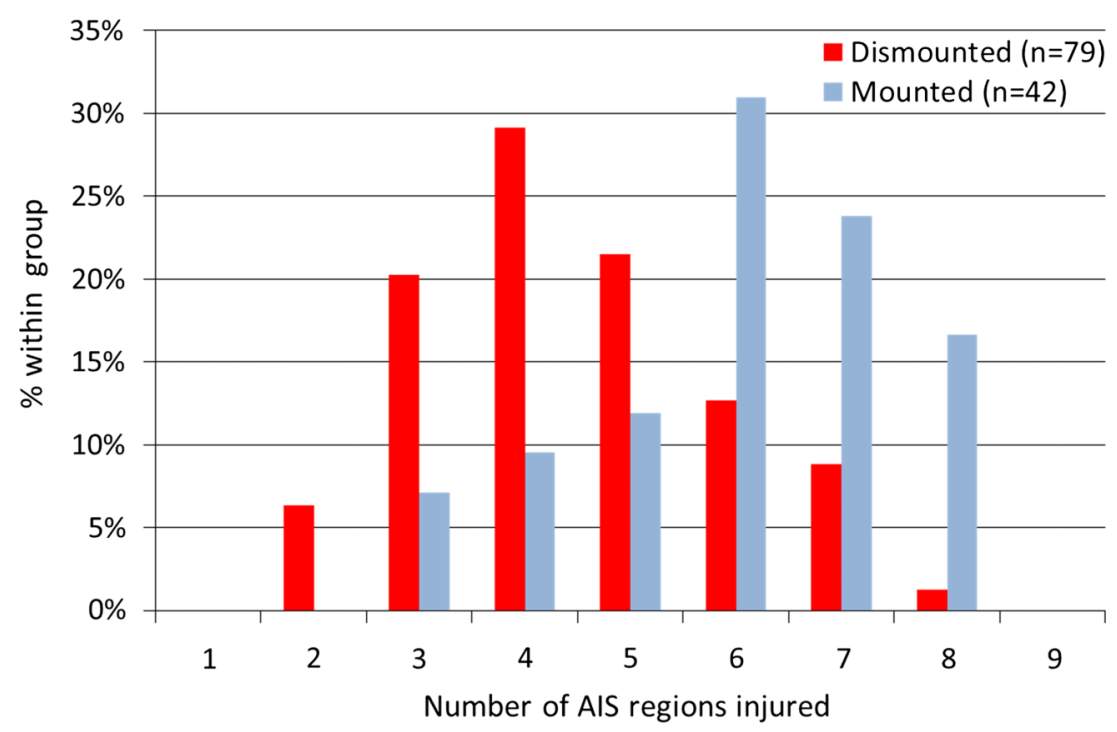


Figure 4 Mechanism of death, mounted versus dismounted.

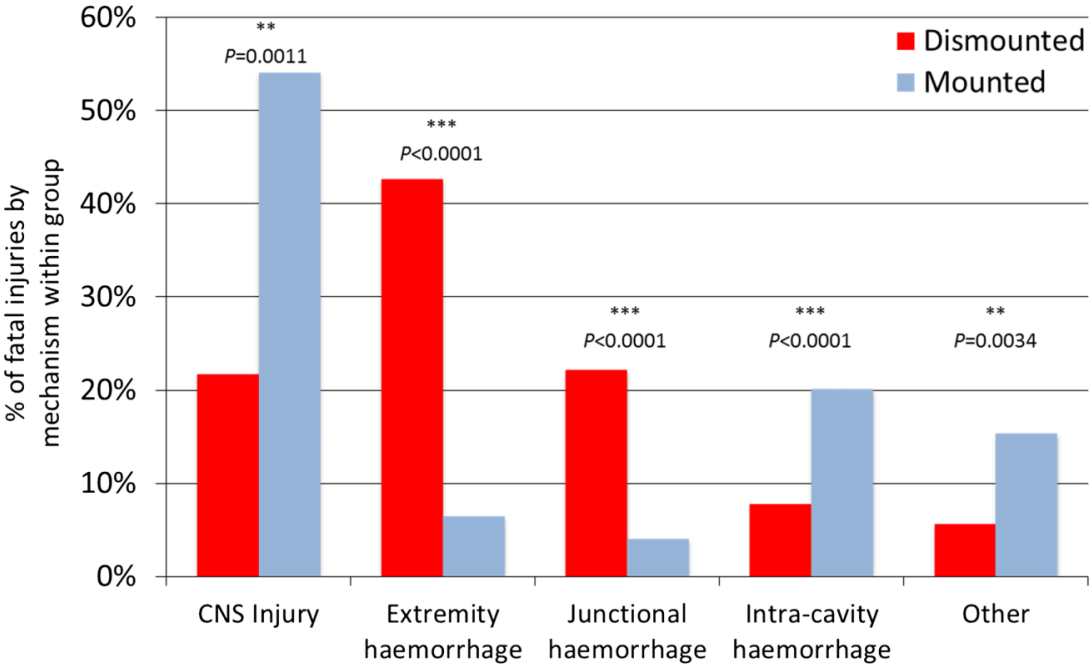

Mechanism of death conventional warfighting and counter insurgency phases of combat. Eastridge $e t a l^{23}$ followed this up in 2012 with an analysis of 4596 US combat fatalities, of which 4016 were killed in action (KIA), again from Iraq and Afghanistan, from October 2001 until June 2011. Data sources included perimortem medical records, autopsy reports and photos. PM-CT was not listed as a data source. Consistent with our methodology, when multiple wounds per casualty were noted, each wound was evaluated individually. There was no differentiation between $\mathrm{M}$ and DM fatalities in either study. Of note in the DOW cohort, 232/558 cases were admitted to medical facilities in extremis with CPR in progress. Cases were classified as 'non-survivable' (NS, 271/558 DOW, 3040/4016 KIA) or 'potentially survivable' (PS, 287/558 DOW, 976/4016 KIA), nomenclature in keeping with previous US-led cause of death analyses. ${ }^{20}$ Again, explosions were the main cause of injury (DOW 72\%, KIA 74\%) followed by GSWs (DOW 25\%, KIA 22\%), and then the other causes (DOW, MVCs 2\%, helicopter crashes 1\%, KIA 'other' (eg, MVC, crush) 4\%). Both DOW and KIA groups showed TBI to be the predominant cause of death in their NS groups ( $83 \%$ and $45 \%$, respectively) and haemorrhage as the main causal mechanism in their PS groups $(80 \%$ and $91 \%$, respectively). This concurs with our conclusions regarding research strategies most likely to decrease mortality from head trauma/TBIprevention-orientated-and haemorrhage-improved haemostatic techniques at all levels of care. Subgroup data of lethal haemorrhage cases were only presented for PS cases, but merits comparison with our study. We demonstrate a higher proportion of extremity haemorrhage cases as a proportion of all haemorrhage cases$52 \%$ - then either the PS DOW group-31\%—or the PS KIA group-13\%, similar rates of junctional haemorrhage $-27 \%$ in our study vs $21 \%$ PS DOW and $19 \%$ PS KIA-and a corresponding lower rate of intracavity haemorrhage-21\% vs $48 \%$ PS DOW and $67 \%$ PS KIA). This may be explained in part by the presence of GSW cases in the DOW and KIA groups and the likely penetrating thoracoabdominal wounding pattern of significant numbers of these cases.

Studies by Bellamy in $1984^{16}$ and more recently by Champion et al in $2003^{24}$ presented summary data of all combat injuries sustained by US Marine and Army personnel in jungle combat in Vietnam from 1967 to 1969 based on clinical records and autopsy data. This database of 7989 patients contains both survivors and fatalities and $\mathrm{M}$ and $\mathrm{DM}$ casualties. The majority were blast injuries (62\% fragment, 3\% (primary) blast) with $23 \%$ GSWs, $6 \%$ burns and 6\% other mechanisms Champion showed a distribution of site of lethal injury as follows: $37 \%$ head, $24 \%$ chest, $9 \%$ abdomen and 3\% extremity. Interestingly, while this is initially similar to modern $\mathrm{M}$ blast fatalities $(52 \%$ head, $25 \%$ chest, $8 \%$ abdomen and $8 \%$ extremity), Champion noted only $17 \%$ with multiple lethal injuries. Furthermore, Bellamy, analysing the same data, observed autopsy findings of multiple potentially fatal wounds in only 30 of 500 cases $(6 \%)$. This contrasts markedly with our study group, in which 70/121 (58\%) of cases sustained two or more potentially fatal injuries. In spite of the Vietnam data including GSW fatalitiesmore likely than blast casualties to sustain a single lethal injury, the increased incidence of multiple lethal injuries per death in the modern data is likely to represent a real difference. This may reflect differing weapons systems responsible for the blast injuries, with greater relative use of conventional ordinance in Vietnam-artillery shells, mortars, grenades, etc-compared to IEDs, the sole injury mechanism in our series.

Such simultaneous commonality and difference emphasises the point that, in battlefield trauma analysis, comparisons between casualties from different theatres of war and certainly from different eras must be made 
with caution, as many factors including weapons systems, tactics, casualty evacuation and medical capabilities must be considered.

\section{Future unexpected survivors}

Blast CNS trauma tended to be of a severe blunt traumatic brain injury pattern and beyond redress with current medical management. Determining precise aetiology in $\mathrm{M}$ fatalities is complex, given victim exposure to multiple modalities with injurious potential. These include primary blast, the shockwave and tertiary blast at multiple instances as a vehicle is first accelerated upwards by the blast wind and then undergoes rapid deceleration on landing. Efforts to reduce mortality and morbidity from these devastating head injuries are likely to be most efficacious if concentrated on prevention and mitigation strategies, such as crew restraint and protection and improved helmet design against blunt trauma, rather than treatment after the blast.

Death in DM troops was most commonly due to haemorrhage, mainly from extremity, then junctional trauma. Our data suggest there is potential to decrease mortality thorough appropriately targeted haemostatic interventions such as compression when possible for these extremity and junctional injuries. There is good evidence that recent (2006 onwards), widespread adoption of prehospital tourniquet use for severe extremity haemorrhage from combat wounds has saved lives. ${ }^{25}$ Civilian medical organisations have traditionally been reluctant to add prehospital tourniquets to their armamentarium. ${ }^{26}$ While indications for tourniquet use may be fewer in civilian trauma, the fact that they have been shown to improve survival following battlefield trauma highlights their potential to do the same in civilian trauma, in appropriate circumstances, and this appears to have been demonstrated by the emergency medical services' response following the Boston Marathon bombing. ${ }^{23}$ It should also be noted that haemorrhage control continues to evolve. A US Food and Drug Administration approved junctional tourniquet, the Combat Ready Clamp (Combat Medical Systems, Fayetteville, North Carolina, USA) is currently being introduced in Afghanistan and truncal tourniquets have been stated as a US Department of Defense research priority. ${ }^{27}$ The effective employment of such devices, if able to achieve prehospital haemostasis for blast casualties and others with haemorrhagic junctional trauma, clearly has the potential to improve survival rates.

In contrast, the majority of mounted deaths from haemorrhage were due to intracavity haemorrhage, likely to have required surgical intervention too early (immediately or within minutes) to be feasible to provide in a contemporary combat environment. Recent operations in Afghanistan have shown casualty evacuation times from the point of wounding to hospital of $75 \mathrm{~min},{ }^{28}$ and this may be an emerging trend in more asymmetric conflicts. However, in more traditional scenarios such as the first Gulf War of 1991, the mean time taken from injury to arriving at a British surgical hospital was $10.2 \mathrm{~h}$ and by the second Gulf War of 2003, with much shorter lines of communication and better casualty evacuation, the mean delay was still $6 \mathrm{~h} .{ }^{29}$ This contrasts markedly with reports from the civilian environment. A study by Demetriades et al in 1996 of 5782 patients in California showed a mean interval of just $37 \mathrm{~min}$ from 911 call notification of emergency medical personnel to arrival at a trauma centre. ${ }^{30}$ Therefore, even interventions with a brief or transient therapeutic window may be of benefit in improving the chances of getting a blast trauma patient with noncompressible bleeding to the surgical team alive. These may include prehospital adoption of haemostatic resuscitation techniques and the use of novel pharmacological agents to prevent/reverse coagulopathy and certainly merit further study. This applies both to the military setting, where several such techniques are already employed or under review, and to civilian trauma, with potential applicability beyond blast trauma. However, the degree of benefit such techniques may confer to the general population, with a broader age range and greater premorbidity when compared to a military cohort, has yet to be determined.

\section{CONCLUSIONS}

IEDs are currently the main cause of death for deployed coalition troops and are likely to remain so for the foreseeable future. Worldwide, IED strikes are also common against civilians. In mounted fatalities following IED strikes, severe head injury was the main cause of death. Given the devastating nature of the associated traumatic brain injury, prevention and mitigation, rather than advances in medical treatment, are the most likely strategies to decrease mortality. Fatal haemorrhage in mounted casualties was most commonly intrathoracic or intra-abdominal, currently only treatable surgically, with no effective prehospital intervention available.

This study has also shown that nearly two-thirds of DM IED fatalities died from exsanguinating extremity or junctional haemorrhage, with lower limb the most common site. Maintaining the drive to improve all haemostatic techniques, from point of wounding to definitive surgical proximal control, alongside development and application of novel haemostatic devices and pharmacological agents could yield a significant survival benefit. This work and such techniques have relevance beyond military medicine to the many civilian trauma services that currently treat IED victims or may have to manage such cases in the future.

\section{Author affiliations}

${ }^{1}$ Imperial College London, Centre for Blast Injury Studies, London, UK

${ }^{2}$ Fort Blockhouse, Defence Centre for Imaging, Gosport, Hampshire, UK

${ }^{3}$ Forensic Pathology Services, Abingdon, Oxfordshire, UK

${ }^{4}$ Academic Department for Military Surgery and Trauma, Royal Centre for Defence Medicine, Birmingham, UK 
Acknowledgements The authors are indebted to Her Majesty's Coroners' Offices for granting access to the PM-CT imaging. We are also extremely grateful to the Academic Department of Military Emergency Medicine (ADMEM) for their kind assistance in extracting casualty data from the UK JTTR.

Contributors JAGS was involved in literature search, figures, study design, data collection, data analysis, data interpretation and writing. IEG and NCAH were involved in data collection and data analysis. AMJB was involved in data interpretation and writing. JCC study design, data interpretation and writing. All authors had full access to the all of the data, and can take responsibility for the integrity of the data and the accuracy of the data analysis. All authors have read and approved the final version of the manuscript.

Funding This research received no specific grant from any funding agency in the public, commercial or not-for-profit sectors.

Competing interests None.

Ethics approval Joint Medical Command, UK Defence Medical Services, and the Royal Centre of Defence Medicine.

Provenance and peer review Not commissioned; internally peer reviewed.

Data sharing statement No additional data are available.

Open Access This is an Open Access article distributed in accordance with the Creative Commons Attribution Non Commercial (CC BY-NC 3.0) license, which permits others to distribute, remix, adapt, build upon this work noncommercially, and license their derivative works on different terms, provided the original work is properly cited and the use is non-commercial. See: http:// creativecommons.org/licenses/by-nc/3.0/

\section{REFERENCES}

1. icasualties.org. online casualty database. http://icasualties.org/OEF/ Fatalities.aspx (accessed 11 Jun 2012).

2. Shelton $\mathrm{HH}$. Pub 3-07.2 Joint tactics, techniques, and procedures for antiterrorism. Washington: Department of Defense, 1998.

3. Ramasamy A, Hill AM, Clasper JC. Improvised explosive devices: pathophysiology, injury profiles and current medical management. J R Army Med Corps 2009;155:265-72.

4. Bosker AJ. IEDs will remain 'weapon of choice' for decades. Joint Improvised Explosive Device Defeat Organisation (JIEDDO), US Department of Defense 21 September 2012. https://www.jieddo.mil/ news_story.aspx?ID=1488 (accessed 15 Dec 2012).

5. Mazurek MT, Ficke JR. The scope of wounds encountered in casualties from the global war on terrorism: from the battlefield to the tertiary treatment facility. J Am Acad Orthop Surg 2006;14:S18-23.

6. Russell RJ. The role of trauma scoring in developing trauma clinica governance in the Defence Medical Services. Philos Trans $R$ Soc Lond B Biol Sci 2011;366:171

7. Wullenweber R, Schneider V, Grumme T. A computer-tomographical examination of cranial bullet wounds. Z Rechtsmed 1977;80:277-46.

8. Farkash U, Scope A, Lynn M, et al. Preliminary experience with postmortem computed tomography in military penetrating trauma. J Trauma 2000;48:303-9.
9. O'Donnell C, Woodford N. Post-mortem radiology-a new sub-speciality? Clin Radiol 2008;63:1189-94.

10. Bolliger SA, Thali MJ, Ross S, et al. Virtual autopsy using imaging: bridging radiologic and forensic sciences. A review of the Virtopsy and similar projects. Eur Radiol 2008;18:273-82.

11. Donchin Y, Rivkind Al, Bar-Ziv J, et al. Utility of postmortem computed tomography in trauma victims. J Trauma 1994;37:552-5; discussion 55-6

12. Jeffery AJ, Rutty GN, Robinson C, et al. Computed tomography of projectile injuries. Clin Radiol 2008;63:1160-6.

13. Champion HR, Holcomb JB, Lawnick MM, et al. Improved characterization of combat injury. J Trauma 2010;68:1139-50.

14. Osler T, Baker SP, Long W. A modification of the injury severity score that both improves accuracy and simplifies scoring. J Trauma 1997;43:922-6.

15. Ramasamy A, Harrisson SE, Clasper JC, et al. Injuries from roadside improvised explosive devices. J Trauma 2008:65:910-14.

16. Bellamy RF. The causes of death in conventional land warfare: implications for combat casualty care research. Mil Med 1984;149:55-62.

17. Mellor S, Cooper G. Analysis of 828 servicemen killed or injured by explosion in Northern Ireland 1970-84: the Hostile Action Casualty System. Br J Surg 1989;76:1006-10.

18. Scholing $M$. The value of postmortem computed tomography as an alternative for autopsy in trauma victims: a systematic review. Eur Radiol 2009;19:2333.

19. Grabherr S, Doenz F, Steger B, et al. Multi-phase post-mortem CT angiography: development of a standardized protocol. Int J Legal Med 2011;125:791-802.

20. Holcomb JB. Causes of death in US Special Operations Forces in the global war on terrorism: 2001-2004. Ann Surg 2007;245:986-91.

21. Nelson TJ, Clark T, Stedje-Larsen ET, et al. Close proximity blast injury patterns from improvised explosive devices in Iraq: a report of 18 cases. J Trauma 2008;65:212-17.

22. Eastridge BJ, Hardin M, Cantrell J, et al. Died of wounds on the battlefield: causation and implications for improving combat casualty care. J Trauma 2011;71:S4-8.

23. Eastridge BJ, Mabry RL, Seguin $P$, et al. Death on the battlefield (2001-2011): implications for the future of combat casualty care. J Trauma 2012;73:S431-7.

24. Champion HR, Bellamy RF, Roberts CP, et al. A profile of combat injury. J Trauma 2003;54:S13-19.

25. Kragh JFJ, Walters TJ, Baer DG, et al. Survival with emergency tourniquet use to stop bleeding in major limb trauma. Ann Surg 2009;249:1-7.

26. Doyle GS, Taillac PP. Tourniquets: a review of current use with proposals for expanded prehospital use. Prehosp Emerg Care 2008;12:241-56.

27. DCBI Task Force. Dismounted Complex Blast Injury (DCBI). Report of the Army DCBI Task Forcl. Fort Sam Houston, Texas: Office of the Surgeon General, 2011.

28. Morrison JJ, Oh J, DuBose JJ, et al. En-route care capability from point of injury impacts mortality after severe wartime injury. Ann Surg 2013;257:330-4.

29. Griffiths D, Clasper J. (iii) Military limb injuries/ballistic fractures. Current Orthopaedics 2006;20:346-53.

30. Demetriades D, Chan L, Cornwell E, et al. Paramedic vs private transportation of trauma patients: effect on outcome. Arch Surg $1996 ; 131: 133-38$. 